\title{
Massive Infected Radicular Cyst of Posterior Maxilla A Case Report
}

Dr. Priyesh Kesharwani ${ }^{*}$, Dr. Siddhartha Bhowmick ${ }^{2}$, Dr. Sreesha $S^{3}$, Dr. VKV Naidu Pentakota ${ }^{4}$, Dr. V K Sasank Kuntamukkula $^{5}$, Dr. Umesh Kaswan ${ }^{6}$

\author{
${ }^{1}$ MDS Oral and Maxillofacial Surgeon, Consultant and Private Practitioner DENT-O-FACIAL Multispeciality Clinic, Mira Road, Thane-Mumbai, India \\ ${ }^{2}$ Senior Lecturer, Department of Conservative and Endodontics, Awadh Dental College and Hospital Jamshedpur, Jharkhand, India \\ ${ }^{3}$ Junior Resident, Department of OMFS MES Dental College, Perinthalmanna, Malappuram, Kerala, India \\ ${ }^{4}$ MDS, Oral and Maxillofacial Surgeon and Implantologist, Maruthi Superspeciality Face, Jaw and Dental Clinic, Opp. RTC Complex Ingate, \\ Anakapalli, Andhra Pradesh, India \\ ${ }^{5}$ MDS, Assistant Professor, Department of Oral and Maxillofacial Surgery, Sri Sai College of Dental Surgery, Vikarabad, India \\ ${ }^{6}$ PG Student, OMFS, Surendra Dental College \& RI, Sriganganagar, Rajasthan, India
}

DOI:10.36348/SJMPS.2019.v05i09.011

| Received: 05.09.2019 | Accepted: 24.09.2019| Published: 30.09.2019

*Corresponding author: Dr. Priyesh Kesharwani

\section{Abstract}

Radicular cysts are the most common odontogenic cysts affecting the oral cavity. They are usually asymptomatic and are diagnosed during routine radiologic examination. Depending on the extent of the lesion, the cyst is managed by nonsurgical or surgical means. Root canal therapy is preferred in a localised lesion whereas in large extensive cysts, enucleation, marsupialization or decompression is done. In this case report, we present the diagnosis and surgical management of a massive infected radicular cyst in the maxillary posterior region.

Keywords: Cyst, Maxilla, Periapical.

Copyright @ 2019: This is an open-access article distributed under the terms of the Creative Commons Attribution license which permits unrestricted use, distribution, and reproduction in any medium for non-commercial use (NonCommercial, or CC-BY-NC) provided the original author and source are credited.

\section{INTRODUCTION}

Odontogenic cysts are the most common type of cysts formed due to the proliferation and cystic degeneration of odontogenic epithelial rest cells. Amongst the odontogenic cysts, radicular cyst is the most common inflammatory odontogenic cysts affecting the jaws. Radicular cyst is also known as apical periodontal cyst and root end cyst, comprises to $50-70 \%$ of the cysts affecting the dentition [1]. They originate from epithelial rests of malassez in the periodontal ligament, as a result of inflammation. Various pathways of spread of pathogenic bacteria have been suggested, from the gingival sulci or periodontal pockets to reach the root canals through severed periodontal blood vessels; through exposed dentinal tubules at the cervical root surface; collectively contributing to the pathogenesis of radicular cyst [2].

Radicular cyst predominantly occurs among men during the fourth and fifth decade of life. In the maxilla, the anterior region is more prone to cyst development whereas in the mandibular region, the radicular cysts occur more frequently in the premolar region. Most radicular cysts are asymptomatic and are detected during examination of non-vital pulps [3, 4].
The surgical treatment of choice for cystic lesions is either enucleation or marsupialization. The choice of treatment is dependent on the size and localization of the lesion, the bone integrity of the cystic wall and its proximity to vital structures. In enucleation, cystic lining is completely removed from its inner bony surface and cavity is filled with blood clot, thus heals by primary intention [5].

\section{CASE REPORT}

A 37 -year-old female patient reported to the Department of Oral Surgery with a chief complaint of swelling over the upper left region of the jaw since 2 weeks. The patient was apparently well 1 month back when she noticed the swelling over the left side of her cheek which gradually increased to present size. It was not associated with any kind of pain. On examination, externally a swelling of $4 \times 3 \mathrm{~cm}$ was present on the left side of cheek, extending from upper lip towards the infraorbital region. It was firm and non-tender on palpation. On intraoral examination, vestibular sulcus was obliterated in the region of maxillary left canine (23) which extended backwards till the maxillary second molar (27). Clinical, subjective and objective examination revealed that left maxillary first premolar (24) was non-vital with grade II mobility, whereas maxillary left lateral incisor (22), canine (23), second 
premolar (25) and first molar (26) were tender on percussion (Figure-1). An occlusal view of the palate (Figure-2) and an orthopantomogram (OPG) (Figur-3) showed a well-defined radiolucency of considerable size extending from right maxillary canine (13) region to the left maxillary molar region (26) and were surrounded with a thin radiopaque border. The patient was subjected to CT scan which showed involvement of whole of the sinus on left side which extended towards the right side sinus, further encroaching upon the roof of the sinus and lateral wall of the nose (Figure $4 \& 5$ ). An incisional biopsy was done for the lesion which was suggestive of infected radicular cyst with left maxillary canine. Treatment plan was formulated and after explaining the same to the patient, her informed consent was taken. Root canal treatment was done for 22, 23, 25 and 26. Due to poor prognosis, left maxillary first premolar was extracted prior to surgery. Patient was prepared for surgical enucleation of radicular cyst under general anesthesia. A mucoperiosteal flap was reflected, followed by removal of bone and exposure of the lesional membrane. The lesional wall was hypertrophic and adhered partly to the mucosa. The lesion was completed degranulated and the cystic lining was enucleated (Figure-6). Flap closure was done with 3-0 silk. Post-operative instructions were given to the patient and were kept on antibiotics and analgesics.

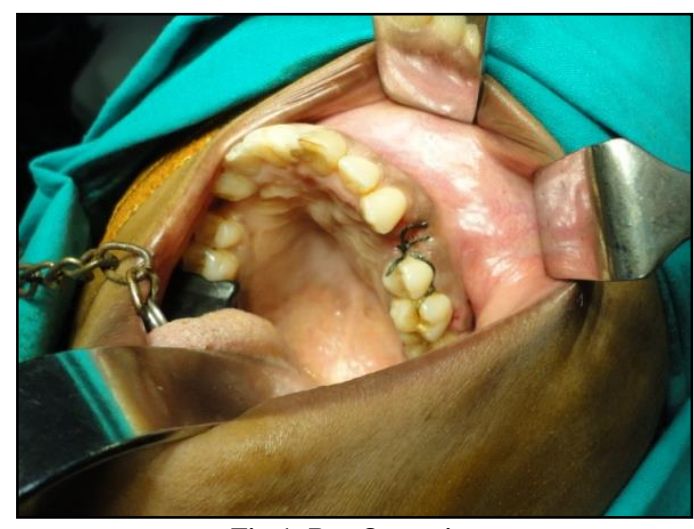

Fig-1: Pre-Operative

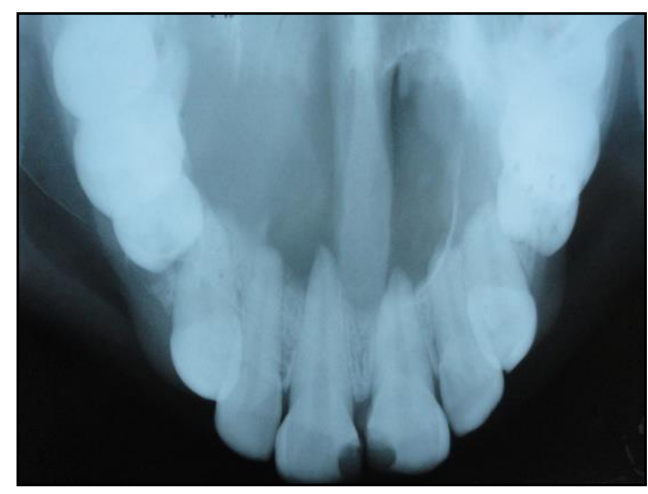

Fig-2: Occlusal Radiograph

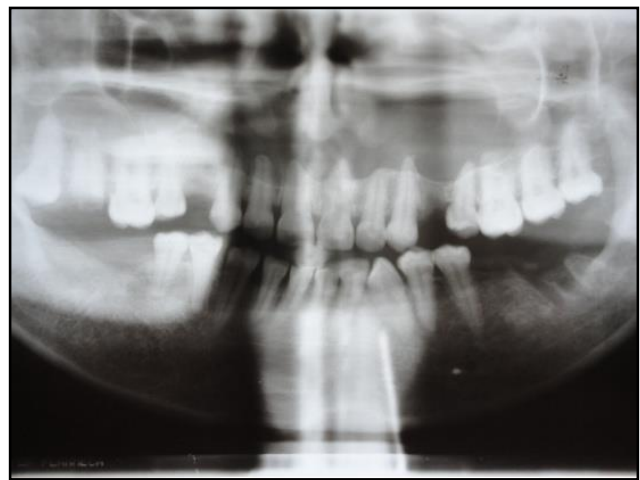

Fig-3: OPG

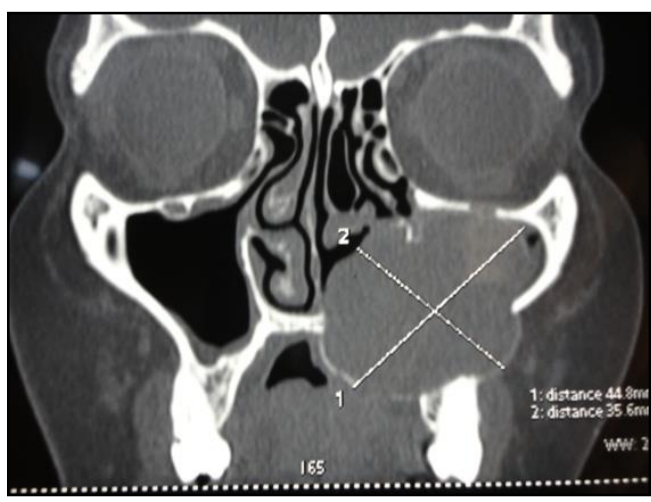

Fig-4: CT SCAN (Coronal View)

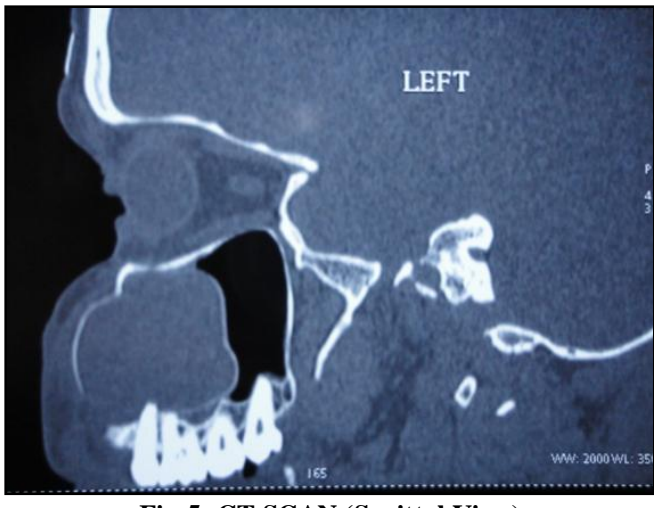

Fig-5: CT SCAN (Sagittal View)

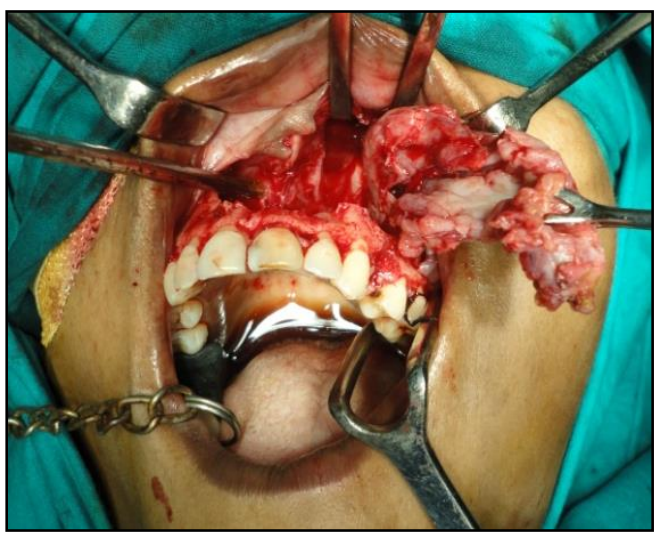

Fig-6: Enucleation of the Cyst 
Priyesh Kesharwani et al; Saudi J Med Pharm Sci, Sep 2019; 5(9): 800-803

\section{DISCUSSION}

Various theories have been postulated to explain the etiopathogenesis of cysts, such as epithelial colonization, epithelial cavitation or the formation of microabcesses. The pathogenesis occurs in three phases, first is the proliferation phase, where the epithelial cell rests of malassez proliferate to form a cavity as a direct result of inflammation. This is influenced by bacterial antigens, epidermal growth factors, metabolic and cellular mediators. In the second phase, a cavity is formed and is lined by epithelium. In the final phase, the cyst grows in size by osmosis [6].

Radiographically, the radicular cyst is a unilocular radiolucent lesion with well-circumscribed radiopaque sclerotic borders. The lesion is associated with the apex of the tooth and a diameter of $\geq 1 \mathrm{~cm}$. This should be differentiated from other odontogenic cysts like dentigerous cysts, odontogenic keratocysts, and odontogenic tumors such as ameloblastoma, Pindborg tumor, and cementomas. Microscopic examination will help differentiate and establish the diagnosis of the lesion [7]. In extensive cases, radiography alone may not be sufficient to show the full extent of the lesions, and advanced imaging may be needed. CT scans provide superior bony detail, allowing for the visualization of the size and extent of the lesion with determination of orbital or nasal involvement. It also aids in planning of a surgical approach [8].

Management of large cystic lesions is a subject of long standing debate. The treatment options for large periapical defects vary depending on the clinical scenarios. A conservative approach includes root canal treatment with long-term calcium hydroxide therapy to drain the cystic fluids [9]. However, such cyst may not heal completely after non-surgical root canal treatment because of incomplete elimination of intracanal or extraradicular infection. Thus, a surgical approach is the preferred line of treatment to treat large periapical cysts, i.e with a diameter of $\geq 20 \mathrm{~mm}$. The surgical options include total enucleation of the lesion, marsupialization for decompression of large cysts or a combination of these approaches. The clinician is often in a dilemma whether to raise a flap and completely enucleate the lesion or to try "decompression" first. If the cyst is subjected to marsupialization with decompression first, size of the lesion is reduced, which will make it less difficult to remove, with less risk of damage to the associated teeth and vital structures. This involves the risk of leaving the cystic cells behind, which may become malignant $[10,11]$. To avoid recurrence, we preferred enucleation of the cyst as the treatment option in the case we reported. This approach provides diagnostic aid for confirming the diagnosis. This raises the issue of perplexity to a dentist whether they should recommend enucleation and biopsy of periapical lesions of endodontic origin or whether conservative treatment should be attempted. Surgery may be suggested only if there is doubt regarding the endodontic origin of the lesions. The literature offers no clear answer to this dilemma. The divergence of criteria and results is probably related due to the presence of both periapical lesions and true periapical cysts in the cases that have been analyzed. Periapical cysts have an epithelial covering and expansive growth but still communicate with the root apex and could therefore be referred to as pseudocysts. A certain percentage of these pseudocysts become involuted with adequate canal treatment. On the other hand, true periapical cysts have no communication with the root canal $[12,13]$.

\section{CONCLUSION}

Hence, through this case report we can conclude that not only the clinical findings but further radiographic investigations such as CT scan are necessary to plan the treatment. In addition, histological examination will help establish the diagnosis. In the case we reported, a massive infected radicular cyst was enucleated from the left maxillary region under general anaesthesia.

\section{REFERENCES}

1. Shaffer. Text Book of Oral and Maxillofacial Pathology. $6^{\text {th }}$ Edition. 487-90.

2. Neville. (2002). Text Book of Oral and Maxillofacial Pathology. $2^{\text {nd }}$ Edition. W.B. Saunders Company. 395-97.

3. Torres-Lagares, D., Segura-Egea, J. J., RodríguezCaballero, A., Llamas-Carreras, J. M., \& Gutiérrez-Pérez, J. L. (2011). Treatment of a large maxillary cyst with marsupialization, decompression, surgical endodontic therapy and enucleation. J Can Dent Assoc, 77(77), b87.

4. Pekiner, F. N., Borahan, O., Ugurlu, F., Horasan, S., Sener, B. C., \& Olgaç, V. (2012). Clinical and radiological features of a large radicular cyst involving the entire maxillary sinus. Clinical and Experimental Health Sciences, 2(1), 31.

5. Uloopi, K. S., Shivaji, R. U., Vinay, C., Shrutha, S. P., \& Chandrasekhar, R. (2015). Conservative management of large radicular cysts associated with non-vital primary teeth: A case series and literature review. Journal of Indian Society of Pedodontics and Preventive Dentistry, 33(1), 53.

6. Parmar, N. K., Nisha, K. J., \& Padmanabhan, S. (2018). The diagnostic dilemma of an infected radicular cyst: A case report.

7. Riachi, F., \& Tabarani, C. (2010). Effective management of large radicular cysts using surgical enucleation VS marsupialisation. International Arab Journal of Dentistry, 1(1).

8. Tian, F. C., Bergeron, B. E., Kalathingal, S., Morris, M., Wang, X. Y., Niu, L. N., \& Tay, F. R. (2019). Management of Large Radicular Lesions Using Decompression: A Case Series and Review 
of the Literature. Journal of endodontics, 45(5), 651-659.

9. Kadam, N. S., De Ataide, I. D. N., Raghava, P., Fernandes, M., \& Hede, R. (2014). Management of large radicular cyst by conservative surgical approach: a case report. Journal of clinical and diagnostic research: JCDR, 8(2), 239.

10. Latoo, S., Shah, A. A., Jan, S. M., Qadir, S., Ahmed, I., Purra, A. R., \& Malik, A. H. (2009). Radicular cyst. JK Science, 11(4), 187.

11. Nainani, P., \& Sidhu, G. K. (2014). Radicular cyst-an update with emphasis on
Pathogenesis. Journal of Advanced Medical and Dental Sciences Research, 2(3).

12. Bhalerao, S., Tamgadge, A., Borse, V., Sandhya, T., Periera, T., Kandekar, P., \& Venkateshwar+, G. An Extensive Radicular Cyst-A Case Report.

13. Koju, S., Chaurasia, N. K., Marla, V., Niroula, D., \& Poudel, P. (2019). Radicular cyst of the anterior maxilla: An insight into the most common inflammatory cyst of the jaws. Journal of Dental Research and Review, 6(1), 26. 